\title{
Blood pressure lowering effects of alpha-lipoic acid supplementation: a meta-analysis of randomized controlled trials
}

\author{
Virginia Boccardi', Mohsen Taghizadeh', Mina Salek', Sadegh Jafarnejad ${ }^{2}$ \\ 'Santa Maria della Misericordia Hospital, Section of Gerontology and Geriatrics, Department of Medicine, University of Perugia, Italy \\ ${ }^{2}$ Research Center for Biochemistry and Nutrition in Metabolic Diseases, Kashan University of Medical Sciences, Kashan, Iran
}

\begin{abstract}
Background: The aim of the present meta-analysis was to detect the effect of $\alpha$-lipoic acid (ALA) supplementation on systolic and diastolic blood pressure (BP).

Material and methods: The related records were selected from several electronic databases from the earliest date 1980 until October 2019. The heterogeneities were assessed by I2 test $(\mathrm{I} 2<50 \%)$ and $\chi^{2}$ test on Cochrane's Q statistic. Standardized mean difference (SMD) and their 95\% confidence intervals (CIs) were considered for net change in systolic blood pressure (SBP) and diastolic blood pressure (DBP). Subgroup analyses were also conducted by baseline BP, health status, doses of supplementation, study duration and supplement utilization.

Results: As a result, a total of 10 studies with 612 subjects were included in the final analysis. Alpha-lipoic acid supplementation significantly reduced SBP (SMD $=-0.50,95 \% \mathrm{CI}:-0.84,-0.16, \mathrm{p}=0.004)$ and $\mathrm{DBP}$ $(\mathrm{SMD}=-0.40,95 \% \mathrm{CI}:-0.71,-0.09, \mathrm{p}=0.01)$, compared to the controls, with the reduction of $6.1 \mathrm{~mm} \mathrm{Hg}$ and $3.6 \mathrm{~mm} \mathrm{Hg}$ of the mean SBP and DBP, respectively. Heterogeneities were explored in both SBP and DBP. Moreover, a statistically significant reduction in $\mathrm{BP}$ was detected in elevated $\mathrm{BP}$ and hypertensive patients as compared with the normotensive subjects.

Conclusion: ALA supplementation could be considered as a BP-lowering agent, especially in subjects with higher blood pressure.
\end{abstract}

Key words: $\alpha$-lipoic acid; blood pressure; systematic review; meta-analysis; RCT

$$
\text { Arterial Hypertens. 2021, vol. 25, no. 1, pages: 29-38 }
$$

DOI: 10.5603/AH.a2021.0001

\section{Introduction}

Alpha lipoic acid (ALA), as a naturally occurring dithiol compound and a organosulfur compound is essential as a cofactor for mitochondrial $\alpha$-ketoacid dehydrogenases [1].

It is synthesized by the liver [2] and is present in animal and vegetable sources [3]. The antioxidant effect of ALA has been demonstrated by the ability of ALA to clear reactive oxygen species (ROS) and activating the endogenous antioxidant system $[4,5]$. Additionally, it has been shown that ALA could improve endothelium function and play a role in nitric oxide synthesis $[6,7]$. According to the latter role, different studies were conducted in vivo, which emphasizes the effect of ALA supplementation on blood

Address for correspondence: Sadegh Jafarnejad, Research Center for Biochemistry and Nutrition in Metabolic Diseases, Kashan University of Medical Sciences, Kashan, I.R. Iran, tel: (+98) 31-55463378, fax: (+98) 31-55463377; e-mail: sjafarnejad@alumnus.tums.ac.ir

This article is available in open access under Creative Common Attribution-Non-Commercial-No Derivatives 4.0 International (CC BY-NC-ND 4.0) license, allowing to download articles and share them with others as long as they credit the authors and the publisher, but without permission to change them in any way or use them commercially 
pressure $(\mathrm{BP})[4,8,9]$. It is well established that hypertension condition (BP) can results in several cardiovascular disorders while decreasing blood pressure reduces cardiovascular risk, myocardial infarction, heart failure, and stroke $[10,11]$. The administration of different doses of ALA has been examined in several studies. Ergür et al. conducted a study in which ALA was administered orally in rats at a dosage of $100 \mathrm{mg} / \mathrm{kg}$, and reported a significant reduction of secondary hypertension [8]. However, the findings of human trials are controversial [12-14]. In a recent study by Mohammadi et al., the daily supplementation of ALA with a dose of $600 \mathrm{mg}$ on subjects with cardiovascular risk factors and chronic spinal cord injury revealed the systolic and diastolic blood pressure lowering effects [12]. However, other trials did not observe any significant blood pressure-lowering effect of ALA supplementation, after four months of oral supplementation with $800 \mathrm{mg}$ ALA [15] and after twenty months of oral supplementation with $1800 \mathrm{mg}$ ALA [16]. Although there is a systematic review showed that supplementation with ALA did not appear to be efficient on BP [4], we conducted the present meta-analysis to better clarify the potential effect of ALA supplementation on BP.

\section{Material and methods}

We carried out the present meta-analysis and designed the strategies according to the PRISMA guidelines [17].

\section{Literature search strategy}

Several electronic databases including Pubmed ${ }^{\mathrm{TM}}$, Scopus $^{\mathrm{TM}}, \mathrm{EMBASE}^{\mathrm{TM}}$, and Google Scholar ${ }^{\mathrm{TM}}$ were searched from inception until October 2019. In addition to electronic searching, we tried to handsearch the reference list and citations of papers to detect more potential eligible studies. Search terms used were as follow: (ALA OR " $\alpha$-lipoic acid" OR "lipoic acid" OR "alpha lipoic acid") AND ("Hemodynamic parameters" OR "Blood pressure" OR "Systolic blood pressure" OR "Diastolic blood pressure" OR "BP" OR “SBP” OR "DBP”).

\section{Selection criteria}

To be included for meta-analysis, the studies had to meet the following inclusion criteria: 1) being a trial in human species with either cross-over or parallel design, 2) providing the possible effects of ALA supplementation on either systolic or diastolic blood pressure, 3) reporting sufficient data on SBP/DBP including baseline/end of supplementation or mean changes and related standard deviations in both intervention and placebo groups, 4) the study had to use a control or placebo group for the treatment group and, 6) subjects had to take ALA supplements for at least 2 weeks. Studies were excluded according to the following criteria: 1) lack of a control group, 2) lack of adequate data regarding SBP or DBP in each group, or lack of required data for computing the indices

\section{Data abstraction}

The data from all included articles were extracted independently by two authors. Any possible disagreement was solved by a third author through consensus and discussion. The following data was obtained from the each of eligible studies: author identification, publication year, study design and location, duration of supplementation and followup, the dose of ALA supplementation, the sample size in both intervention and control groups, demographic indices (age, gender), clinical condition, baseline SBP, and DBP values, and observed significant outcomes.

\section{Validity assessment}

We estimated the quality of studies according to the Jadad scale with the following criteria: (1) randomization (one score for mentioning random allocation and one more score for explaining the method of randomization appropriately), (2) blinding (One score for stating that the trial was blinded and one more score for describing the method of blinding properly, and (3) reporting of dropouts, in addition to reasons for withdrawals (one score for reporting of dropouts and the withdrawal reasons). The total score varies between 0 to 5 , in which the trials with the score of $\geq 3$ are considered as high-quality trials.

\section{Data synthesis}

We analyzed the data using two software including RM Software (Review Manager 5.3) and Biostat Comprehensive Meta-Analysis. We defined the treatment effects by standardized mean difference (SMD) and $95 \%$ confidence intervals (CIs) of outcomes. Moreover, we assessed the possible heterogeneity by $\chi^{2}$ test on Cochrane's $\mathrm{Q}$ statistic and I2 test, by which $\mathrm{p}<0.05$ or $\mathrm{I} 2>50 \%$ was considered as heterogeneous. We used the random-effects model to calculate the pooled effect size. Moreover, we conducted subgroup and sensitivity analyses in accordance with the Cochrane guidelines for exploring any possible sources of heterogeneity between included studies [18]. We performed the sensitivity analysis by removing a single included trial and re-calculating the effect 
size to detect any potential effect on the final overall effect size [19].

To find any potential publication biases, Begg's rank correlation test, funnel plots, and Egger's regression test were used. A p value $<0.05$ was considered as statistically significant.

\section{Results}

\section{Selection of trials}

Figure 1 shows the process of trial selection. In general, a number of 218 articles were primarily detected, in which 194 articles were excluded due to duplication $(\mathrm{n}=101)$ or were irrelevant to the current metaanalysis including non-original research (letters, case reports, and series, reviews, experimental or animal studies) ( $\mathrm{n}=93)$. More studies were excluded because of the following reasons: inappropriate reporting data on SBP or DBP, supplementation of ALA in less than two weeks, improper study design such as non-randomized trial, and lack of control group. Finally, ten studies were included in the meta-analysis [12-16, 20-24].

\section{Characteristics of included trials/quality assessment}

The descriptions of all included studies of the current meta-analysis are shown in Table 1 . The year of publication of included studies varied between 1997 and 2019, of which five studies were conducted in Iran $[12-14,21,24]$, two in the USA
$[20,22]$, and the remaining included studies were carried out in the Republic of Korea [16], Italy [23] and Germany [15].

Totally, ten clinical trials with 612 subjects (Intervention, $\mathrm{n}=311$, and control, $\mathrm{n}=301$ ), were included in the present synthesis. The number of participants in included trials ranged from 7 to 82 subjects. Supplementation duration was between 8 weeks to 20 weeks, and the dose of supplementation varied from 300 to $1800 \mathrm{mg} / \mathrm{d}$. Of the ten included trials, five recruited Type 2 Diabetic patients [13-16, $20]$, one trial was performed in chronic spinal cord injury patients [12], one trial included subjects with stroke [24], two studies elected participants with obesity $[16,23]$, the patients with metabolic syndrome and coronary artery disease were used in one study [22] and one more trial was conducted in patients with rheumatoid arthritis [21]. The mean age of subjects varied between 11.5 to 62.3 years. Among included trials, in accordance with the updated guidelines of the American College of Cardiology/American Heart Association (ACC/AHA); two have been categorized as elevated blood pressure subjects [20,21], one study as normotensive subjects [23], and seven remaining studies as hypertensive patients which ranged from 117 to 144 and 69.4 to 87.85 for systolic and diastolic blood pressure, respectively $[12-16,22,24]$. The quality of studies was assessed using the Jadad score scale. According to Jadad scale method, all included studies were categorized as high-quality studies (Tab. 2). Six out of 10 included trials described the blinding method

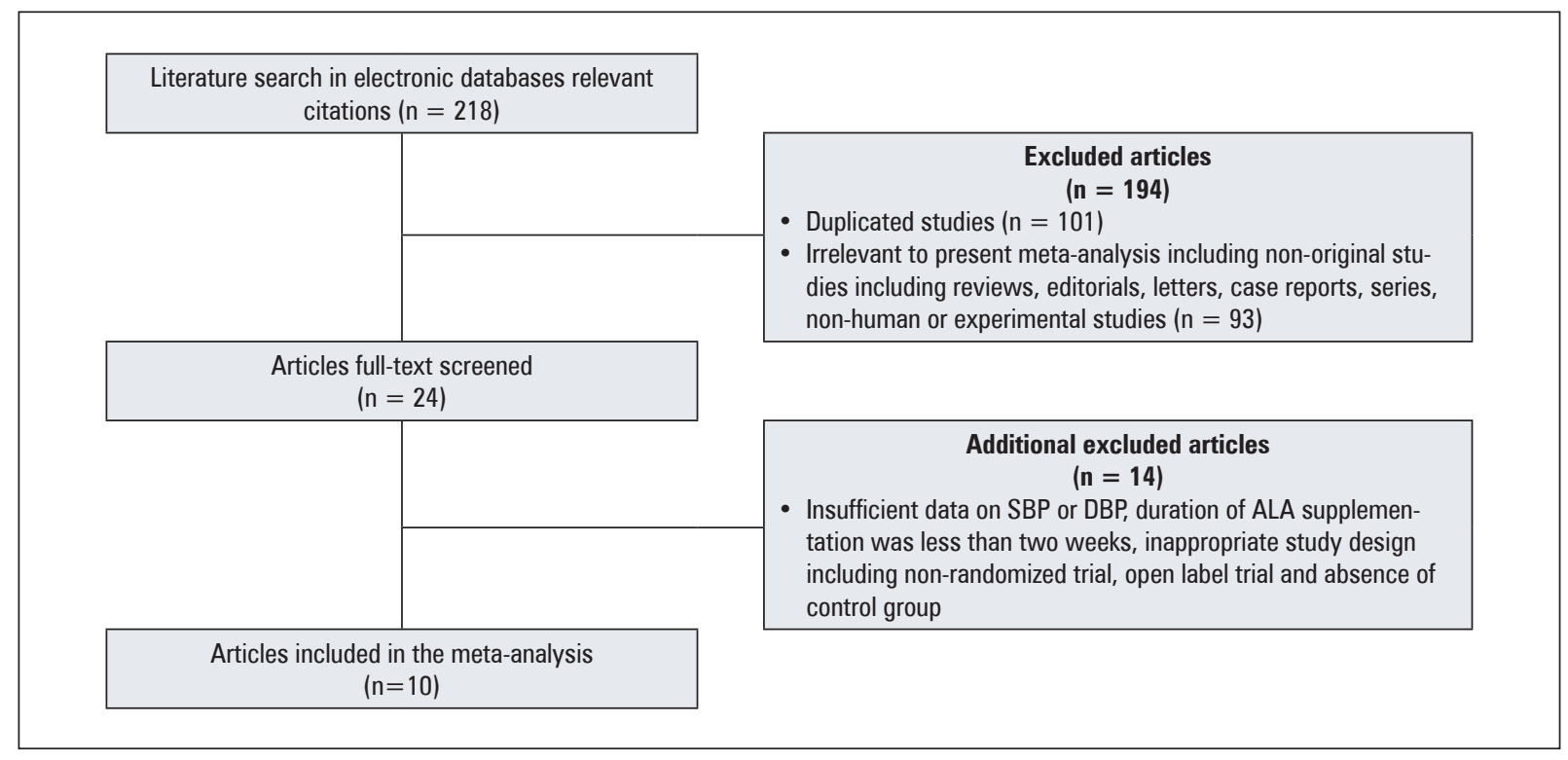

Figure 1. The flow diagram of literature search and study selection of the meta-analysis. SBP — systolic blood pressure; DBP — diastolic blood pressure; ALA $-\alpha$-lipoic acid 


\begin{tabular}{|c|c|c|c|c|c|c|c|c|c|c|}
\hline 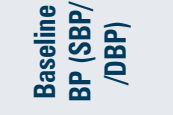 & 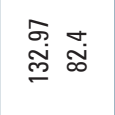 &  & 总 $\bar{\infty}$ & $\overline{\underline{p}} \bar{r}$ & 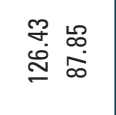 & 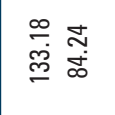 & $\exists R$ & 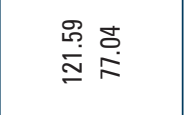 & 三 。 & $\underset{\Phi}{\stackrel{d}{\infty}}$ \\
\hline 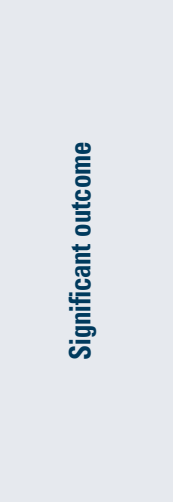 & 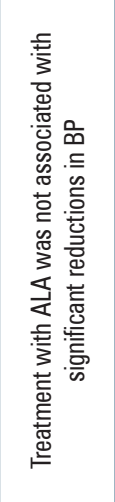 & 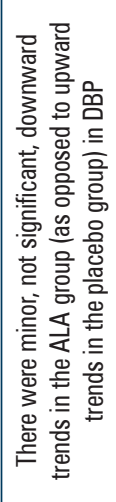 & 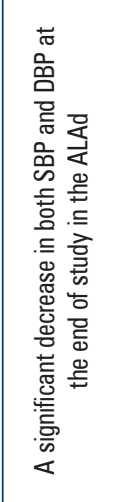 &  & 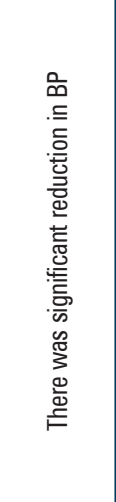 & 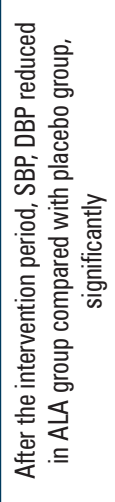 & 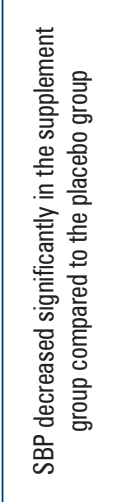 &  & 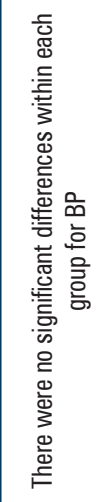 & 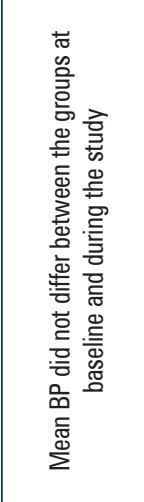 \\
\hline 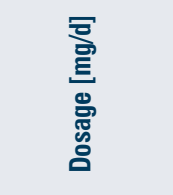 & 品 & 응 & 各 & 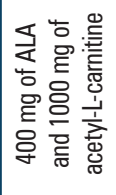 & 응 & 응 & 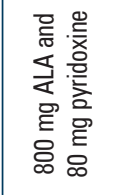 & 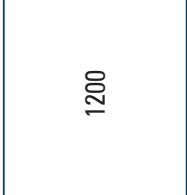 & 용 & 요 \\
\hline  &  & 言 & 高 & 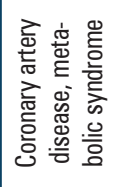 & 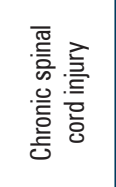 & 总 & 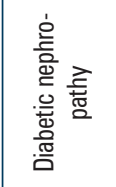 & 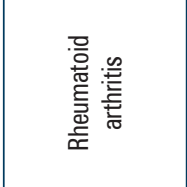 &  & 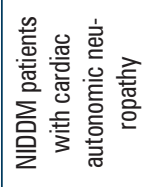 \\
\hline 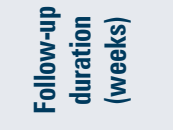 & ని & 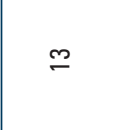 & $\infty$ & $\infty$ & $\simeq$ & $\simeq$ & $\simeq$ & $\infty$ & $\simeq$ & 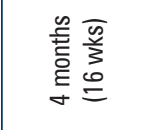 \\
\hline 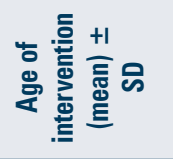 & $\stackrel{\nabla}{\vec{\sigma}}$ & 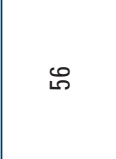 & g & $\widetilde{\sigma}$ & ஜ్ల &  & : & 总 & $\stackrel{\leftrightarrow}{=}$ & $\stackrel{?}{\leftrightarrow}$ \\
\hline 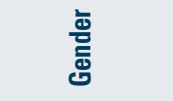 & $\Sigma u$ & $\sum u$ & $\Sigma u$ & $\Sigma u$ & $\Sigma$ & $\Sigma u$ & $\sum u$ & 4 & $\Sigma u$ & $\Sigma u$ \\
\hline 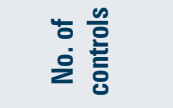 & $\cong$ & r & $\stackrel{\sim}{\sim}$ & $\bar{\sim}$ & 户ి &  & $=$ & $\approx$ & $\tilde{ల}$ & 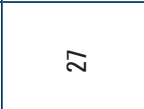 \\
\hline 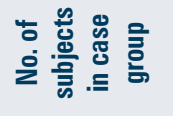 & $\approx$ & $\underline{m}$ & ని & $\stackrel{2}{\llcorner}$ & $\stackrel{\infty}{\sim}$ & ల్ల & $=$ & ల్ల & $\tilde{ల}$ & 尺 \\
\hline 产 & 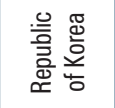 & 芯 & 흔 & 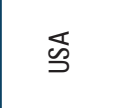 & 흔 & 흔 & 흠 & 흔 & 롶 & 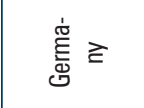 \\
\hline 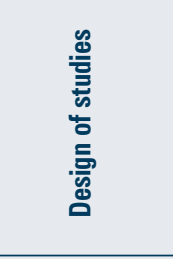 & 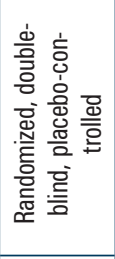 & 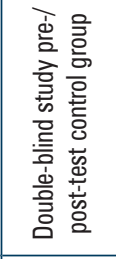 & 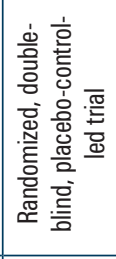 &  & 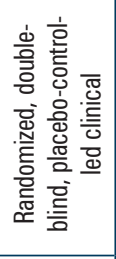 &  & 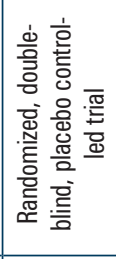 & 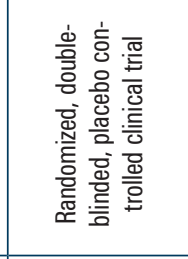 & 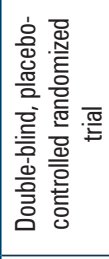 &  \\
\hline 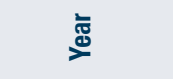 & $\overline{\text { సे }}$ & 今̊․ & 灾 & 空 & 号 & $\stackrel{\infty}{\overline{2}}$ & $\stackrel{m}{\grave{n}}$ & $\stackrel{\llcorner}{\grave{2}}$ & 홓 & 兽 \\
\hline 毫 & 홍 & $\begin{array}{l}\text { 鸢 } \\
\text { 鄫 }\end{array}$ & 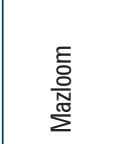 & $\begin{array}{l}\frac{5}{0} \\
\sum_{0}^{\frac{5}{0}} \\
\sum\end{array}$ & 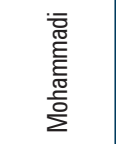 & 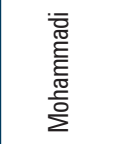 & 产 &  & 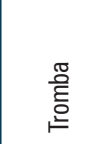 & $\begin{array}{l}\frac{\mathrm{m}}{\mathrm{s}} \\
\frac{\mathrm{g}}{\mathrm{N}}\end{array}$ \\
\hline
\end{tabular}


Table 2. Quality of the 10 studies as assessed by the Jadad score

\begin{tabular}{|l|c|c|c|c|}
\hline Study [year] & Blinding & Randomization & $\begin{array}{c}\text { Withdrawals and } \\
\text { dropouts descriptions }\end{array}$ & Score \\
\hline Koh [2011] & 2 & 2 & 1 & 5 \\
\hline Lukaszuk [2009] & 2 & 1 & 1 & 4 \\
\hline Mazloom [2009] & 1 & 2 & 1 & 4 \\
\hline McMackin [2007] & 2 & 2 & 1 & 5 \\
\hline Mohammadi [2015] & 1 & 2 & 1 & 5 \\
\hline Mohammadi [2018] & 2 & 2 & 0 & 3 \\
\hline Noori [2013] & 1 & 2 & 1 & 5 \\
\hline Pourghasem [2015] & 2 & 2 & 1 & 5 \\
\hline Tromba [2019] & 2 & 2 & 1 & 4 \\
\hline Ziegler [1997] & 1 & 2 & & 4 \\
\hline
\end{tabular}

appropriately [16, 20-24] and most of the included studies (9 of 10) provided a sufficient and acceptable description of the method of randomization [12-16, 21-24]. All studies except one study [13] stated the dropouts descriptions and the associated reasons.

\section{Blood pressure-lowering effects of ALA supplementation}

The synthesis was carried out based on the data of 612 participants from 10 clinical trials reporting blood pressure values (intervention, $\mathrm{n}=311$, and placebo, $\mathrm{n}=301$ ). As it has been shown in Figure 2, ALA supplementation statistically significantly reduced both SBP (SMD $=-0.50,95 \%$ CI: -0.84 , $-0.16, \mathrm{p}=0.004)$ with the reduction of $6.1 \mathrm{~mm} \mathrm{Hg}$ in the SBP mean and DBP (SMD $=-0.40,95 \%$ CI: $-0.70,-0.09, \mathrm{p}=0.01$ ) with the reduction of and $3.6 \mathrm{~mm} \mathrm{Hg}$ in the DBP mean. Additionally, a significant heterogeneity was observed between the included studies regarding both SBP and DBP (SBP: $\mathrm{p}<0.001, \mathrm{I} 2=74 \%$ and DBP: $\mathrm{p}<0.001, \mathrm{I} 2=69 \%$ ). According to the Cochrane guidelines, we conducted a stratified analysis to detect possible sources of heterogeneity.

\section{Stratified analysis}

Stratified analyses according to baseline blood pressure, follow-up duration, the dosage of supplementation, clinical conditions, and supplement utilization were conducted to explore the effect of ALA supplementation on blood pressure (Tab. 3). In accordance with the updated guidelines of the American College of Cardiology/American Heart Association (ACC/AHA), three subsets were investigated as normotensive, elevated BP, and hypertensive patients. Considering the baseline blood pressure, subgroups of elevated BP and hypertensive patients showed statistically significant reduction in blood pressure as compared with normotensive patients [elevated BP: SMD of DBP, -0.6 (95\% CI: $-1.04,-0.16$, p $=0.008)$, hypertensive subjects: SMD of SBP, -0.64 (95\% CI: $-1.03,-0.25, \mathrm{p}=0.001)$, SMD of DBP, -0.44 (95\% CI: $-0.83,-0.05, \mathrm{p}=0.03)$ ].

The supplementation duration was separated into $\leq 12$ weeks and > 12 weeks. With respect to clinical condition of subjects, two specific groups were divided to non-diabetic/diabetic subjects. As far as the dose of supplementation was considered, higherdose (> $600 \mathrm{mg} /$ day) and lower-dose $(\leq 600 \mathrm{mg} /$ day $)$ were separated as two distinct subsets. As presented in Table 3, There was a considerable reduction in subgroups of studies categorized in respect to duration of supplementation of $\leq 12$ weeks [SMD of SBP, -0.67 (95\% CI: $-1.10,-0.23, \mathrm{p}=0.003)$, SMD of DBP, -0.52 (95\% CI: $-0.92,-0.13, \mathrm{p}=0.01$ )], ALA dose of $\leq 600 \mathrm{mg} /$ day weeks [SMD of SBP, -0.80 (95\% CI: $-1.22,-0.37, \mathrm{p}<0.001)$, SMD of DBP, -0.71 (95\% CI: $-1.14,-0.29, \mathrm{p}<0.001)]$, and non-diabetic subjects [SMD of SBP, $-0.62(95 \%$ CI: $-1.22,-0.02, \mathrm{p}=0.04)$, SMD of DBP, -0.63 (95\% CI: $-1.15,-0.11, \mathrm{p}=0.02)$ ]. Subgroup analysis according to different utilization (single/multicomponent) of supplements revealed both systolic and diastolic-lowering effect of single component supplementation [SMD of SBP, -0.48 (95\% CI: $-0.87,-0.08, \mathrm{p}=0.02)$, SMD of DBP, $-0.46(95 \%$ CI: $-0.82,-0.10, \mathrm{p}=0.01)$ ].

\section{Sensitivity analysis}

We performed a sensitivity analysis to investigate the effect of each trial on the estimated overall pooled effect size. Removal of each study and re-calculating the effect size did not show any significant alteration in the overall effects of ALA supplementation on SBP 
A $\mathrm{SBP}$

Study name Outcome

Std diff Standard
in means error

in means error Variance limit limit

$\begin{array}{lllll}0.152- & 0.161 & 0.026 & 0.468- & 0.163\end{array}$

Koh 2011(b) SBP

Lukaszuk 2009 SBP

Mazloom 2009 SBP

MCMackin 2007 SBP

Mohammadi 2015 SBP

Mohammadi 2018 SBP

Noori $2013 \quad$ SBP

Pourghasem 2015 SBP

Tromba 2019 SBP

Ziegler 1997 SBP
$0.152-$

$-0.013$

$0.802-$

$0.346-$

$1.345-$

$1.137-$

$0.850-$

0.653 -

0.338

$-0.048$

0.502 -
Statistics for each study

0.469

0.275
0.341

0.291

0.263

0.358

0.255

0.252

0.267

0.174
$0.220 \quad 0.932-\quad 0.906$

$0.076 \quad 1.342-0.263$

$\begin{array}{lll}0.116 & 1.014- & 0.321\end{array}$

0.085 1.916- 0.775 -

0.069 1.653- 0.621

$0.128 \quad 1.551-0.148$ -

$0.065 \quad 1.152-0.154$

$\begin{array}{llll}0.063 & 0.156- & 0.831\end{array}$

$0.072 \quad 0.572-0.476$

$0.030 \quad 0.843-0.160$ -
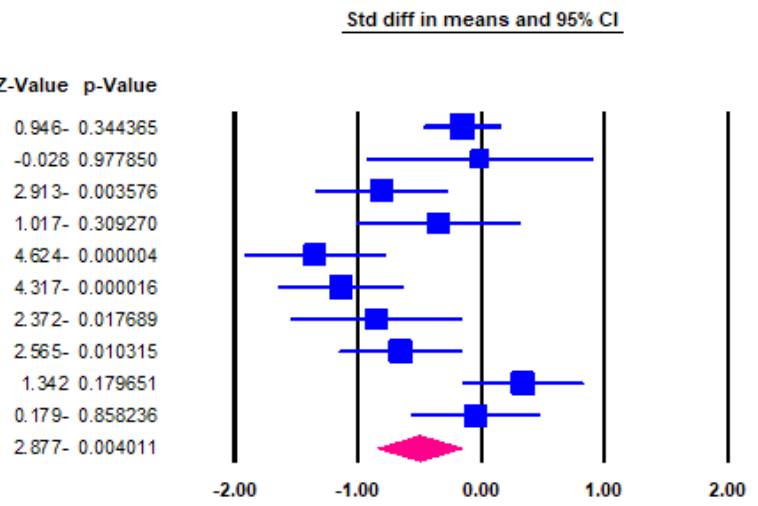

Favours intervention Favours control

B DBP

\begin{tabular}{|c|c|}
\hline Study name & Outcome \\
\hline Koh 2011(b) & DEP \\
\hline Luksszuk 2009 & DEP \\
\hline Mszloom 2009 & DEP \\
\hline MaMadkin 2007 & DEP \\
\hline Mohammadi 2015 & DEP \\
\hline Mohammadi 2018 & DEP \\
\hline Noori 2013 & DEP \\
\hline Pourghasem 2015 & DEP \\
\hline Tromba 2019 & DEP \\
\hline Ziegler 1997 & DEP \\
\hline
\end{tabular}

$\begin{array}{cc}\begin{array}{cc}\text { Std diff } \\ \text { in means }\end{array} & \begin{array}{c}\text { Standard } \\ \text { error }\end{array} \\ 0.221- & 0.161 \\ 0.302- & 0.471 \\ 0.455- & 0.268 \\ 0.235- & 0.339 \\ 1.253- & 0.287 \\ 1.139- & 0.263 \\ 0.000 & 0.343 \\ 0.695- & 0.255 \\ 0.128 & 0.250 \\ 0.182 & 0.268 \\ 0.404 & 0.158\end{array}$

Statistics for each study Lower Upper ariance limit limit Z-Value p-Value $\begin{array}{lll}0.026 \quad 0.537- & 0.096\end{array}$ $0.222 \quad 1.226-\quad 0.621$ $0.072 \quad 0.981-\quad 0.071$ $\begin{array}{lll}0.115 & 0.900- & 0.429\end{array}$ 0.083 1.817- 0.690 0.069 1.658. 0.623 . $\begin{array}{lll}0.118 & 0.672- & 0.672\end{array}$ 0.065 1.195. 0.194 . $\begin{array}{lll}0.063 & 0.383 & 0.618\end{array}$ $\begin{array}{lll}0.072 & 0.343- & 0.707\end{array}$ $0.025 \quad 0.713 .-0.094$

$\begin{array}{cc}1.387- & 0.172 \\ 0.642- & 0.521 \\ 1.698- & 0.090 \\ 0.694- & 0.488 \\ 4.381- & 0.000 \\ 4.325- & 0.000 \\ 0.000 & 1.000 \\ 2.719- & 0.007 \\ 0.511 & 0.610 \\ 0.680 & 0.497 \\ 2.553- & 0.011\end{array}$

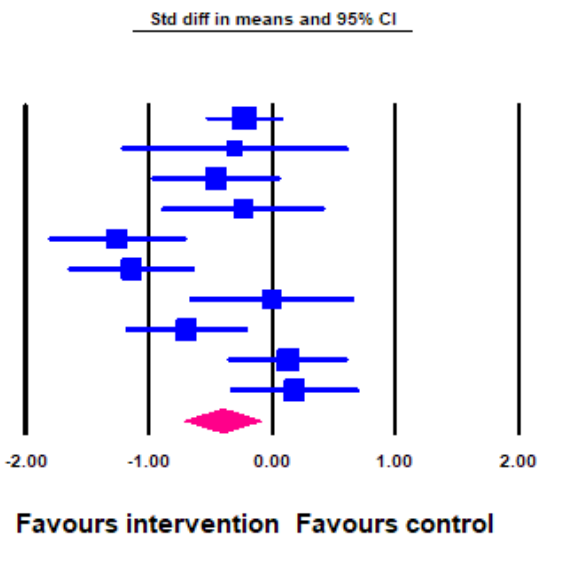

Figure 2. Forest plot of comparison of blood pressure between ALA supplementation and control groups. A. Systolic blood pressure (SPB); B. Diastolic blood pressure (DBP). Random effects model was used to pool the standard mean differences of indicators. $\mathrm{Cl}$ - confidence interval; I — squared inconsistency

with the range of $-0.40(95 \% \mathrm{CI}=-0.72,-0.08)$ to $-0.60(95 \% \mathrm{CI}=-0.92,-0.27)$ and $\mathrm{DBP}$ with the range of $-0.31(95 \% \mathrm{CI}=-0.59,0.02)$ to -0.47 , $95 \% \mathrm{CI}=-0.79,-0.15)$ (Fig. 3).

\section{Publication bias}

We investigated the publication bias of the present meta-analysis by the funnel plot analysis. As it has been shown in Figure 4, the symmetrical pattern of funnel plots regarding to both SBP and DBP hypnotized that there are no specific potential biases in the included trials. Moreover, Egger's linear regression for both SBP (intercept: -1.98 ; standard error: $2.41 ; 95 \% \mathrm{CI}:-7.54,3.58 ; \mathrm{t}=0.82, \mathrm{df}=8$; two-tailed $\mathrm{p}=0.43$ ) and DBP (intercept: -0.71 ; standard error: $2.31 ; 95 \% \mathrm{CI}:-6.05,4.62 ; \mathrm{t}=0.30$, $\mathrm{df}=8$; two-tailed $\mathrm{p}=0.76$ ) confirm the finding. Additionally, Begg's rank correlation test did not explore potential publication bias (SBP: Kendall's Tau with continuity correction: $-0.22 ; \mathrm{z}=0.89$; two-tailed $\mathrm{p}=0.37$ ); DBP: Kendall's Tau with continuity correction: $-0.08 ; \mathrm{z}=0.35$; two-tailed $\mathrm{p}=0.72$ ).

\section{Discussion}

This is the comprehensive systematic review and meta-analysis which summarizes the data from 10 trials involving a total of 612 subjects.

The results of the present meta-analysis reveal that ALA supplementation causes a significant reduction in DBP in elevated BP subjects and a reduction in SBP and marginally DBP in hypertensive subjects. The definition and explanation of hypertension have been changed in the past years. One of the most recent definitions belongs to the American College of Cardiology and American Heart Association (ACC/ (AHA). This is an updated version of the guidelines 
Table 3. Subgroup analysis

\begin{tabular}{|c|c|c|c|c|c|c|}
\hline & & & WMD (95\% CI) & Test for overall effect & Test for heterogeneity & $I^{2}(\%)$ \\
\hline \multirow{6}{*}{ Baseline BP } & \multirow{2}{*}{ Normal } & SBP & $0.33[-0.16,0.83]$ & $p=0.19$ & Not applicable & Not applicable \\
\hline & & DBP & $0.13[-0.36,0.62]$ & $p=0.61$ & Not applicable & Not applicable \\
\hline & \multirow{2}{*}{ Elevated } & SBP & $-0.45[-1.02,0.12]$ & $p=0.12$ & $p=0.24$ & 29 \\
\hline & & DBP & $-0.60[-1.04,-0.16]$ & $p=0.008$ & $p=0.46$ & 0 \\
\hline & \multirow{2}{*}{ Hypertension } & SBP & $-0.64[-1.03,-0.25]$ & $p=0.001$ & $p<0.001$ & 74 \\
\hline & & DBP & $-0.44[-0.83,-0.05]$ & $p=0.03$ & $p<0.001$ & 74 \\
\hline \multirow{4}{*}{$\begin{array}{l}\text { Follow-up } \\
\text { duration } \\
\text { [weeks] }\end{array}$} & \multirow{2}{*}{$\leq 12$} & SBP & $-0.67[-1.10,-0.23]$ & $p=0.003$ & $p<0.001$ & 76 \\
\hline & & DBP & $-0.52[-0.92,-0.13]$ & $p=0.010$ & $p=0.001$ & 72 \\
\hline & \multirow{2}{*}{$>12$} & SBP & $-0.11[-0.37,0.14]$ & $p=0.39$ & $p=0.92$ & 0 \\
\hline & & DBP & $-0.13[-0.39,0.13]$ & $p=0.34$ & $p=0.42$ & 0 \\
\hline \multirow{4}{*}{$\begin{array}{l}\text { Dosage } \\
{[\mathrm{mg} / \mathrm{d}]}\end{array}$} & \multirow{2}{*}{$\leq 600$} & SBP & $-0.80[-1.22,-0.37]$ & $p<0.001$ & $p=0.06$ & 57 \\
\hline & & DBP & $-0.71[-1.14,-0.29]$ & $p<0.001$ & $p=0.05$ & 58 \\
\hline & \multirow{2}{*}{$>600$} & SBP & $-0.23[-0.59,0.13]$ & $p=0.21$ & $p=0.03$ & 64 \\
\hline & & DBP & $-0.14[-0.43,0.16]$ & $p=0.36$ & $p=0.11$ & 47 \\
\hline \multirow{4}{*}{$\begin{array}{l}\text { Clinical } \\
\text { condition }\end{array}$} & \multirow{2}{*}{ Diabetic patients } & SBP & $-0.35[-0.69,-0.01]$ & $p=0.04$ & $p=0.11$ & 46 \\
\hline & & DBP & $-0.17[-0.39,0.05]$ & $p=0.13$ & $p=0.53$ & 0 \\
\hline & \multirow{2}{*}{$\begin{array}{l}\text { Non-diabetic } \\
\text { subjects }\end{array}$} & SBP & $-0.62[-1.22,-0.02]$ & $p=0.04$ & $p<0.0001$ & 84 \\
\hline & & DBP & $-0.63[-1.15,-0.11]$ & $p=0.02$ & $p=0.001$ & 78 \\
\hline \multirow{4}{*}{ Supplement } & \multirow{2}{*}{$\begin{array}{l}\text { Single supple- } \\
\text { ment }\end{array}$} & SBP & $-0.48[-0.87,-0.08]$ & $p=0.02$ & $p<0.001$ & 79 \\
\hline & & DBP & $-0.46[-0.82,-0.10]$ & $p=0.01$ & $p<0.001$ & 75 \\
\hline & \multirow{2}{*}{ Multi supplement } & SBP & $-0.57[-1.06,-0.09]$ & $p=0.02$ & $p=0.32$ & 0 \\
\hline & & DBP & $-0.12[-0.59,0.36]$ & $p=0.63$ & $p=0.63$ & 0 \\
\hline
\end{tabular}

BP — blood pressure; SBP — systolic blood pressure; DBP — diastolic blood pressure; SMD — standard mean difference; $\mathrm{Cl}$ — confidence interval; $\mathrm{I}^{2}$ — percentage score for heterogeneity

related to the prevention, evaluation, detection, and management of hypertension in adults. This is distinguished by removing the category of prehypertension and separating it into two distinct levels: elevated blood pressure/stage 1 hypertension [25].

The association of hypertension and elevated blood pressure with morbidity and mortality of cardiovascular disorders has been well established [11, 26]. Abundant Epidemiologic data support that the risk of cardiovascular disorders disease increases with elevating blood pressure values. It has been reported that the blood pressure starting at $\geq 115 / 75 \mathrm{~mm}$ $\mathrm{Hg}$ results in such a manner $[11,27,28]$. There are evidence that both oxidative stress and a diminished capacity for scavenging free radicals play major roles in the development of hypertension and cardiovascular disorders. Moreover, SBP and DBP have been reported to positively relate to oxidative stress markers and negatively relate to plasma antioxidant capacity and free radicals could participate in the development of hypertension complications [29, 30].

Disruption of endothelial function leads to a diminished production or availability of $\mathrm{NO}$ and sub- sequent impaired NO bioactivity. This results in an imbalance between the endothelium- vasoconstrictors, and vasodilators derived from endothelium [30]. Multiple cardiovascular risk factors are related to the possible changes in endothelial function including sedentary and inappropriate lifestyle, hypercholesterolemia, aging, arterial hypertension, and a family history of atherosclerotic disorders [31]. Thus, most updated guidelines suggest improvements in lifestyle including limiting daily dietary sodium, exercise, and reasonable weight-loss in high-risk patients.

According to the previous evidence, ALA is considered as an efficient antioxidant with both lipid and aqueous solubility [4]. Furthermore, ALA supplementation may exert anti-inflammatory and hypoglycemic characteristics of the subjects with various conditions [32]. Beyond the main function of ALA as an antioxidant $[33,34]$, ALA can also increase NO synthesis which results in an improvement in endothelial function [35]. Moreover, many enzymatic and metabolic reactions are dependent on ALA as a potential co-enzyme, and enhancing agent in the 
A

\begin{tabular}{|c|c|c|c|c|c|c|c|c|}
\hline \multirow[t]{2}{*}{ Study name } & \multirow[t]{2}{*}{ Outcome } & \multirow[b]{2}{*}{ Point } & \multicolumn{6}{|c|}{ Statistics with study removed } \\
\hline & & & $\begin{array}{l}\text { Standard } \\
\text { error }\end{array}$ & Variance & $\begin{array}{l}\text { Lower } \\
\text { limit }\end{array}$ & $\begin{array}{l}\text { Upper } \\
\text { limit }\end{array}$ & Z-Value & p-Value \\
\hline Koh 2011(b) & SBP & $0.550-$ & 0.197 & 0.039 & $0.937-$ & $0.164-$ & $2.789-$ & 0.005285 \\
\hline Lukaszuk 2009 & SBP & $0.539-$ & 0.184 & 0.034 & $0.899-$ & $0.178-$ & $2.929-$ & 0.003401 \\
\hline Mazloom 2009 & SBP & $0.467-$ & 0.190 & 0.036 & $0.840-$ & -0.095 & $2.460-$ & 0.013886 \\
\hline McMackin 2007 & SBP & $0.518-$ & 0.191 & 0.036 & $0.891-$ & $0.144-$ & $2.716-$ & 0.006607 \\
\hline Mohammadi 2015 & SBP & $0.406-$ & 0.164 & 0.027 & $0.728-$ & -0.085 & $2.477-$ & 0.013240 \\
\hline Mohammadi 2018 & SBP & $0.426-$ & 0.174 & 0.030 & $0.767-$ & -0.084 & $2.441-$ & 0.014665 \\
\hline Noori 2013 & SBP & $0.468-$ & 0.186 & 0.035 & $0.834-$ & $0.103-$ & 2.511- & 0.012028 \\
\hline Pourghasem 2015 & SBP & $0.484-$ & 0.195 & 0.038 & $0.866-$ & $0.102-$ & $2.486-$ & 0.012925 \\
\hline Tromba 2019 & SBP & $0.603-$ & 0.166 & 0.027 & $0.927-$ & $0.278-$ & 3.634- & 0.000279 \\
\hline Ziegler 1997 & SBP & $0.555-$ & 0.189 & 0.036 & $0.926-$ & $0.184-$ & $2.933-$ & 0.003352 \\
\hline & & $0.502-$ & 0.174 & 0.030 & $0.843-$ & $0.160-$ & $2.877-$ & 0.0040 \\
\hline
\end{tabular}

B

Study name Outcome

\begin{tabular}{|c|c|c|c|c|c|}
\hline \multicolumn{6}{|c|}{ Statistics with study removed } \\
\hline $\begin{array}{cc}\text { Standard } \\
\text { Point } & \text { error }\end{array}$ & Variance & $\begin{array}{c}\text { Lower } \\
\text { limit }\end{array}$ & $\begin{array}{l}\text { Upper } \\
\text { limit }\end{array}$ & Z-Value & p-Value \\
\hline 0.186 & 0.035 & $0.794-$ & -0.065 & $2.307-$ & $0.02105 c$ \\
\hline 0.168 & 0.028 & $0.741-$ & -0.080 & 2.438 - & 0.01477 \\
\hline 0.177 & 0.031 & $0.744-$ & -0.051 & $2.246-$ & 0.024710 \\
\hline 0.172 & 0.030 & $0.758-$ & $0.082-$ & 2.436 - & 0.014836 \\
\hline 0.144 & 0.021 & $0.593-$ & $0.028-$ & 2.151- & 0.031450 \\
\hline 0.149 & 0.022 & $0.607-$ & -0.025 & $2.127-$ & $0.03346 c$ \\
\hline 0.169 & 0.029 & $0.774-$ & 0.111 & 2.619 & 0.008827 \\
\hline 0.173 & 0.030 & $0.708-$ & -0.029 & $2.126-$ & 0.033476 \\
\hline 0.164 & 0.027 & $0.791-$ & $0.146-$ & 2.849 & 0.004387 \\
\hline 0.162 & 0.026 & $0.790-$ & $0.154-$ & $2.907-$ & 0.003645 \\
\hline 0.158 & 0.025 & $0.713-$ & -0.094 & 2.553 & 0.010668 \\
\hline
\end{tabular}

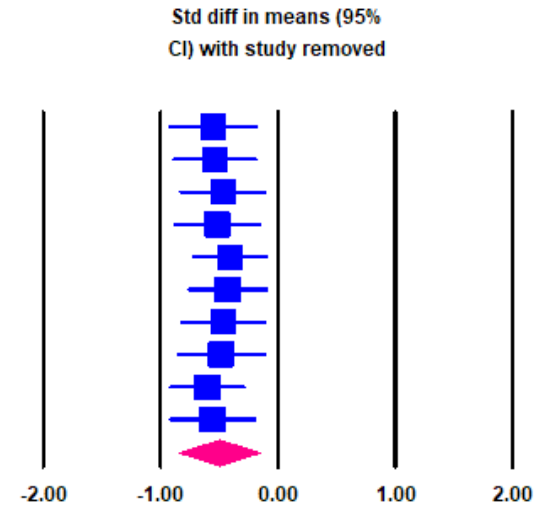

Favours intervention Favours control Cl) with study removed

$\mid$
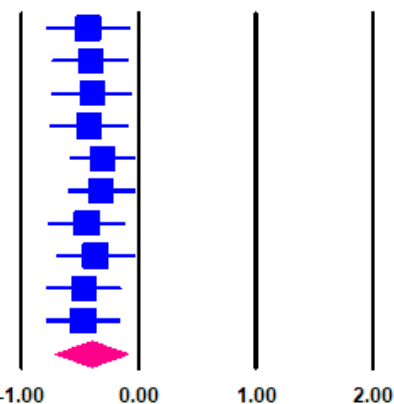

Favours intervention Favours control

Figure 3. Sensitivity analysis for the effect of $\alpha$-lipoic acid (ALA) supplementation on systolic blood pressure (SBP) (A) and diastolic blood pressure (DBP) (B)

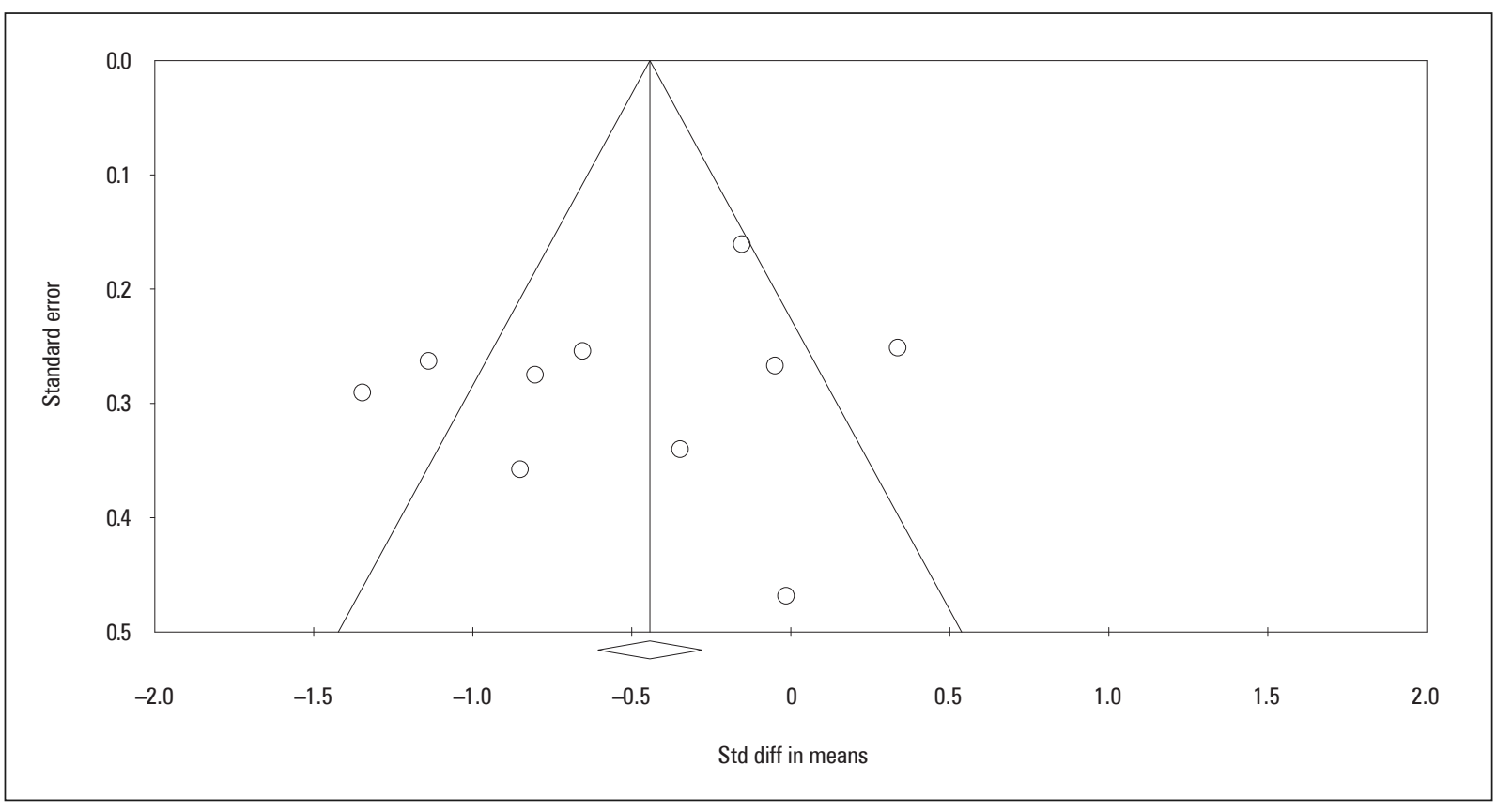

Figure 4. Funnel plot detailing publication bias of included studies. SMD — standard mean difference; SE — standard error 
regeneration of endogenous antioxidants including vitamin $\mathrm{C}$, vitamin $\mathrm{E}$, and glutathione [36]. As stated before, ALA supplementation may play a role in anti-inflammatory mechanisms. Interestingly, these mechanisms are considered as the potential predictors of cardiovascular disorders and type II diabetes development [37-39]. In general, our meta-analysis reveals the reductions in DBP and SBP after ALA supplementation in elevated BP and hypertensive subjects, respectively; however, the blood lowering effect of ALA supplementation was not observed in normotensive subjects. Therefore, this could be assumed that ALA supplementation may have the beneficial effects on lowering blood pressure when the hypertension is manifested as both subclinical and clinical condition. ALA may exert its antihypertensive and hypoglycemic effects and the subsequent anti-cardiovascular effects by an attenuation of the oxidative stress which is reflected by the decrement in the basal O2- synthesis in vessels and by the retention of the gluthatione-peroxidase activity of the plasma [9].

Despite some strengths of the present meta-analysis, multiple limitations should be noted. First, most of the included trials enrolled limited participants, which result in misleading in final estimates of treatment effects, as trials with small sample sizes might be methodologically less considerable and are prone to report the values somewhat larger than their actual effect sizes. Moreover, the heterogeneity between included studies was considerable even after performing subgroup analyses which may potentially reduce the influence of the final results.

Nonetheless, the present analysis had some strength: the first point is that we systematically and comprehensively searched through several databases. Defined inclusion criteria/clear approach in gathering data and in-depth quality assessment of studies are considered as other points. Finally, lacking the potential biases should be considered as another strength point.

\section{Conclusion}

The current meta-analysis observed a beneficial effect of ALA supplementation in lowering BP in subjects with elevated blood pressure. The beneficial effect of this compound in alleviating blood pressure is maybe by its anti-oxidative and vascular endothelial properties. However, future precision randomized trials should establish whether different doses of ALA or longer-term supplementation of ALA could provide a hypotensive role and reduce cardiovascular risk.

\section{Conflict of interest}

No conflict of interest was declared regarding the present manuscript.

\section{References}

1. Smith AR, Shenvi SV, Widlansky M, et al. Lipoic acid as a potential therapy for chronic diseases associated with oxidative stress. Curr Med Chem. 2004; 11(9): 11351146, doi: 10.2174/0929867043365387, indexed in Pubmed: 15134511.

2. Brownlee M, Aiello LP, Cooer ME. Complications of Diabetes Mellitus. In: Melmed S, Polonsky KS, Larsen PR. ed. Williams Textbook of Endocrinology. 13 ed. Content Reository Only!, Philadelhia 2016: 1484-581.

3. Shamsizadeh A, Roohbakhsh A, Ayoobi F. The Role of Natural Products in the Prevention and Treatment of Multiple Sclerosis. In: Watson RR, Killgore W. ed. Nutrition and Lifestyle in Neurological Autoimmune Diseases. Academic Press 2017: 249-60.

4. Mohammadi V, Dehghani S, Askari G. Does Alpha-lipoic Acid Supplement Regulate Blood Pressure? A Systematic Review of Randomized, Double-blind Placebo-controlled Clinical Trials. Int J Prev Med. 2017; 8: 33, doi: 10.4103/2008-7802.206138, indexed in Pubmed: 28584615.

5. Moini H, Packer L, Saris NEL. Antioxidant and prooxidant activities of alpha-lipoic acid and dihydrolipoic acid. Toxicol Appl Pharmacol. 2002; 182(1): 84-90, doi: 10.1006/taap.2002.9437, indexed in Pubmed: 12127266.

6. Skibska B, Goraca A. The protective effect of lipoic acid on selected cardiovascular diseases caused by age-related oxidative stress. Oxid Med Cell Longev. 2015; 2015: 313021, doi: 10.1155/2015/313021, indexed in Pubmed: 25949771.

7. Badran M, Abuyassin B, Golbidi S, et al. Alpha Lipoic Acid Improves Endothelial Function and Oxidative Stress in Mice Exposed to Chronic Intermittent Hypoxia. Oxid Med Cell Longev. 2019; 2019: 4093018, doi: 10.1155/2019/4093018, indexed in Pubmed: 31093313.

8. Ergür BU, Çilaker Mıcılı S, Yılmaz O, et al. The effects of $\alpha$ lipoic acid on aortic injury and hypertension in the rat remnant kidney (5/6 nephrectomy) model. Anatol J Cardiol. 2015; 15(6): 443-449, doi: 10.5152/akd.2014.5483, indexed in Pubmed: 25430409.

9. El Midaoui A, de Champlain J. Prevention of hypertension, insulin resistance, and oxidative stress by alpha-lipoic acid. $\mathrm{Hy}$ pertension. 2002; 39(2): 303-307, doi: 10.1161/hy0202.104345, indexed in Pubmed: 11847202.

10. Dorans KS, Mills KT, Liu Y, et al. Trends in Prevalence and Control of Hypertension According to the 2017 American College of Cardiology/American Heart Association (ACC/AHA) Guideline. J Am Heart Assoc. 2018; 7(11), doi: 10.1161/JAHA.118.008888, indexed in Pubmed: 29858369.

11. Antonakoudis G, Poulimenos L, Kifnidis K, et al. Blood pressure control and cardiovascular risk reduction. Hippokratia. 2007; 11(3): 114-119, indexed in Pubmed: 19582204.

12. Mohammadi V, Khalili M, Eghtesadi S, et al. The effect of alphalipoic acid (ALA) supplementation on cardiovascular risk factors in men with chronic spinal cord injury: a clinical trial. Spinal Cord. 2015; 53(8): 621-624, doi: 10.1038/sc.2015.35, indexed in Pubmed: 25753493.

13. Noori N, Tabibi H, Hosseinpanah F, et al. Effects of combined lipoic acid and pyridoxine on albuminuria, advanced glycation end-products, and blood pressure in diabetic nephropathy. Int J Vitam Nutr Res. 2013; 83(2): 77-85, doi: 10.1024/0300-9831/ a000147, indexed in Pubmed: 24491880. 
14. Mazloom Z, Ansar H. The effect of alpha-lipoic acid on blood pressure in type 2 diabetics. Iran J Endocrinol Metab. 2009; 11(3).

15. Ziegler D, Schatz H, Conrad F, et al. Effects of treatment with the antioxidant alpha-lipoic acid on cardiac autonomic neuropathy in NIDDM patients. A 4-month randomized controlled multicenter trial (DEKAN Study). Deutsche Kardiale Autonome Neuropathie. Diabetes Care. 1997; 20(3): 369-373, doi: 10.2337/ diacare.20.3.369, indexed in Pubmed: 9051389.

16. Koh EH, Lee WJe, Lee SAh, et al. Effects of alpha-lipoic acid on body weight in obese subjects. Am J Med. 2011; 124(1): 85.e1-85.e8, doi: 10.1016/j.amjmed.2010.08.005, indexed in Pubmed: 21187189

17. Moher D, Liberati A, Tetzlaff J, et al. PRISMA Group. Preferred reporting items for systematic reviews and meta-analyses: the PRISMA statement. Ann Intern Med. 2009; 151(4): 264-9, W64, doi: 10.7326/0003-4819-151-4-200908180-00135, indexed in Pubmed: 19622511.

18. Gopalakrishnan S, Ganeshkumar P. Systematic Reviews and Metaanalysis: Understanding the Best Evidence in Primary Healthcare. J Family Med Prim Care. 2013; 2(1): 9-14, doi: 10.4103/22494863.109934, indexed in Pubmed: 24479036.

19. Jafarnejad S, Tsang C, Taghizadeh M, et al. A meta-analysis of cumin (Cuminum cyminim L.) consumption on metabolic and anthropometric indices in overweight and type 2 diabetics. J Funct Foods. 2018; 44: 313-321, doi: 10.1016/j.jff.2018.03.026.

20. Lukaszuk J, Schultz T, Prawitz A, et al. Effects of R-Alpha Lipoic Acid on HbA1c, Lipids and Blood Pressure in Type-2 Diabetics: A Preliminary Study. J Complement Integrat Med. 2009; 6(1), doi: 10.2202/1553-3840.1297.

21. Pourghasem Ga, Aliasghari F, Kolahi S, et al. Effects of alphalipoic acid supplementation on blood pressure and some inflammatory factors in women with rheumatoid arthritis. Arak Medical University Journal (AMUJ). 2015; 17(93): 9-18.

22. McMackin CJ, Widlansky ME, Hamburg NM, et al. Effect of combined treatment with alpha-Lipoic acid and acetyl-L-carnitine on vascular function and blood pressure in patients with coronary artery disease. J Clin Hypertens (Greenwich). 2007; 9(4): 249-255, doi: 10.1111/j.1524-6175.2007.06052.x, indexed in Pubmed: 17396066.

23. Tromba L, Perla FM, Carbotta G, et al. Effect of Alpha-Lipoic Acid Supplementation on Endothelial Function and Cardiovascular Risk Factors in Overweight/Obese Youths: A Double-Blind, Placebo-Controlled Randomized Trial. Nutrients. 2019; 11(2), doi: 10.3390/nu11020375, indexed in Pubmed: 30759784.

24. Mohammadi V, Khorvash F, Feizi A, et al. Does Alpha-lipoic Acid Supplementation Modulate Cardiovascular Risk Factors in Patients with Stroke? A Randomized, Double-blind Clinical Trial. Int J Prev Med. 2018; 9: 34, doi: 10.4103/ijpvm.IJPVM_32_17, indexed in Pubmed: 29721235.

25. Whelton PK, Carey RM, Aronow WS, et al. 2017 ACC/AHA/ AAPA/ABC/ACPM/AGS/APhA/ASH/ASPC/NMA/PCNA guideline for the prevention, detection, evaluation, and management of high blood pressure in adults: a report of the American College of Cardiology/American Heart Association Task Force on Clinical Practice Guidelines. J Am Coll Cardiol. 2018; 71(19): e127-e248, doi: 10.1016/j.jacc.2017.11.006, indexed in Pubmed: 29146535.

26. Vasan RS, Larson MG, Leip EP, et al. Assessment of frequency of progression to hypertension in non-hypertensive participants in the Framingham Heart Study: a cohort study. Lancet. 2001;
358(9294): 1682-1686, doi: 10.1016/S0140-6736(01)06710-1, indexed in Pubmed: 11728544.

27. Franco OH, Peeters A, Bonneux L, et al. Blood pressure in adulthood and life expectancy with cardiovascular disease in men and women: life course analysis. Hypertension. 2005; 46(2): 280-286, doi: 10.1161/01.HYP.0000173433.67426.9b, indexed in Pubmed: 15983235.

28. Staessen JA, Li Y, Thijs L, et al. Blood pressure reduction and cardiovascular prevention: an update including the 2003-2004 secondary prevention trials. Hypertens Res. 2005; 28(5): 385-407, doi: 10.1291/hypres.28.385, indexed in Pubmed: 16156503.

29. Rodrigo R, Prat H, Passalacqua W, et al. Relationship between oxidative stress and essential hypertension. Hypertens Res. 2007; 30(12): 1159-1167, doi: 10.1291/hypres.30.1159, indexed in Pubmed: 18344620.

30. Senoner T, Dichtl W. Oxidative Stress in Cardiovascular Diseases: Still a Therapeutic Target? Nutrients. 2019; 11(9), doi: 10.3390/ nu11092090, indexed in Pubmed: 31487802.

31. Favero G, Paganelli C, Buffoli B, et al. Endothelium and its alterations in cardiovascular diseases: life style intervention. Biomed Res Int. 2014; 2014: 801896, doi: 10.1155/2014/801896, indexed in Pubmed: 24719887.

32. Mendoza-Núñez VM, García-Martínez BI, Rosado-Pérez J, et al. The Effect of $600 \mathrm{mg}$ Alpha-lipoic Acid Supplementation on Oxidative Stress, Inflammation, and RAGE in Older Adults with Type 2 Diabetes Mellitus. Oxid Med Cell Longev. 2019; 2019: 3276958, doi: 10.1155/2019/3276958, indexed in Pubmed: 31285784.

33. Packer L, Roy S, Sen CK. $\alpha$-Lioic acid: a metabolic antioxidant and otential redox modulator of transcrition. Adv Pharmacol. 1996; 38: 79-101, doi: 10.1016/S1054-3589(08)60980-1.

34. Packer L, Witt EH, Tritschler HJ. alpha-Lipoic acid as a biological antioxidant. Free Radic Biol Med. 1995; 19(2): 227-250, doi: 10.1016/0891-5849(95)00017-r, indexed in Pubmed: 7649494.

35. Heitzer T, Finckh B, Albers S, et al. Beneficial effects of alphalipoic acid and ascorbic acid on endothelium-dependent, nitric oxide-mediated vasodilation in diabetic patients: relation to parameters of oxidative stress. Free Radic Biol Med. 2001; 31(1): 53-61, doi: 10.1016/s0891-5849(01)00551-2, indexed in Pubmed: 11425490 .

36. Biewenga GP, Haenen GR, Bast A. The pharmacology of the antioxidant lipoic acid. Gen Pharmacol. 1997; 29(3): 315-331, doi: 10.1016/s0306-3623(96)00474-0, indexed in Pubmed: 9378235.

37. Rader DJ. Inflammatory markers of coronary risk. N Engl J Med. 2000; 343(16): 1179-1182, doi: 10.1056/ NEJM200010193431609, indexed in Pubmed: 11036126.

38. Ridker PM, Buring JE, Cook NR, et al. C-reactive protein, the metabolic syndrome, and risk of incident cardiovascular events: an 8-year follow-up of 14719 initially healthy American women. Circulation. 2003; 107(3): 391-397, doi: 10.1161/01.cir.0000055014.62083.05, indexed in Pubmed: 12551861.

39. Schmidt MI, Duncan BB, Sharrett AR, et al. Markers of inflammation and prediction of diabetes mellitus in adults (Atherosclerosis Risk in Communities study): a cohort study. Lancet. 1999; 353(9165): 1649-1652, doi: 10.1016/s0140-6736(99)01046-6, indexed in Pubmed: 10335783. 